Federal Reserve Bank of Minneapolis
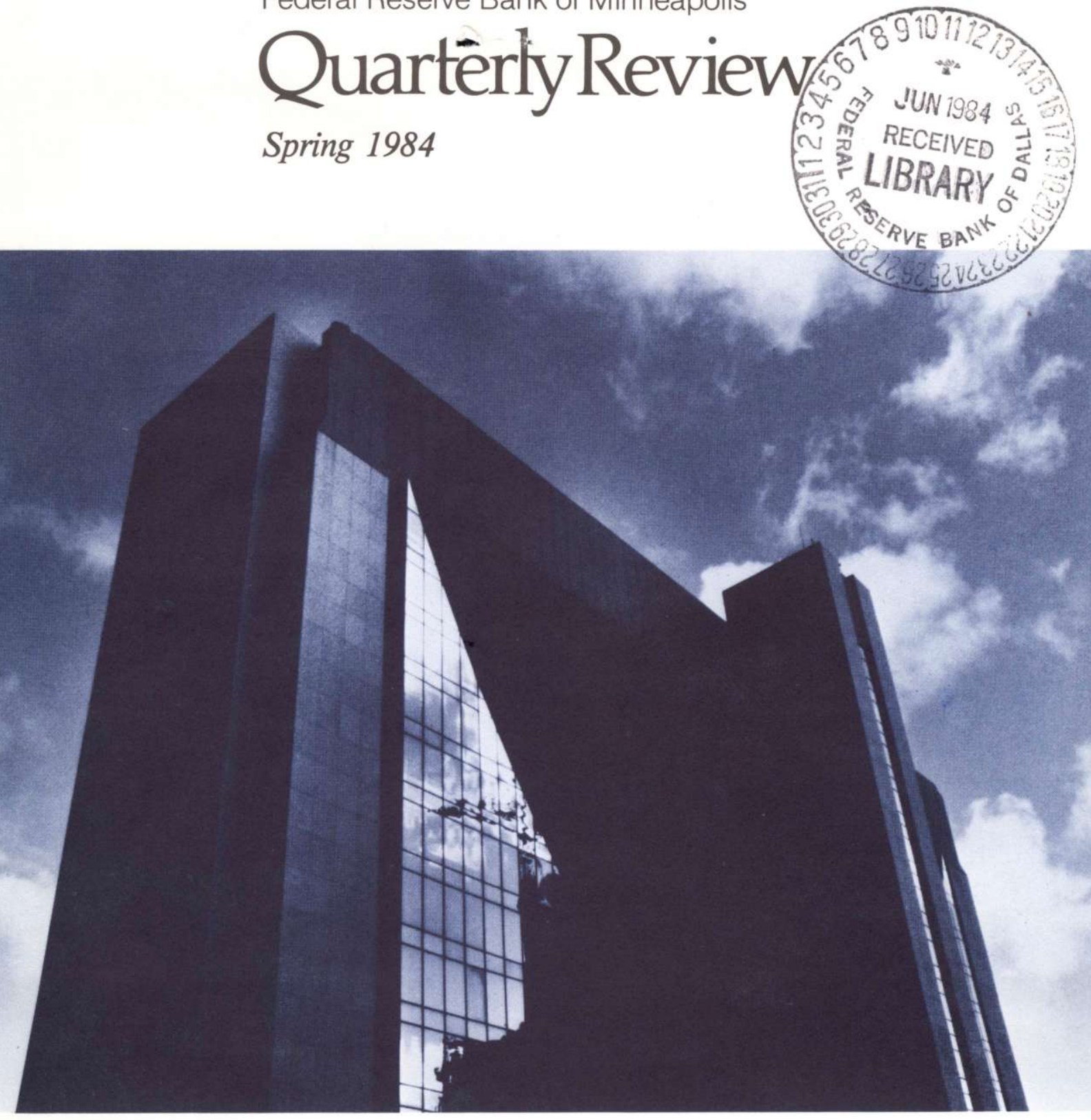

Should Currency Be Priced Like Cars?

Thomas M. Supel Richard M. Todd

Some Pleasant Monetarist Arithmetic Michael R. Darby (p. 15) A Reply to Darby

Preston J. Miller Thomas J. Sargent (p. 21)

District Conditions

Urban Strength, Rural Weakness

(p. 27) 
Federal Reserve Bank of Minneapolis

\section{Quarterly Review Vol. 8, No. 2 ISSN 0271-5287}

This publication primarily presents economic research aimed at improving policymaking by the Federal Reserve System and other governmental authorities.

Produced in the Research Department. Edited by Preston J. Miller and Inga Velde.

Graphic design by Phil Swenson and typesetting by Barbara Cahlander and Terri Desormey, Graphic Services Department.

Address requests for additional copies to the Research Department,

Federal Reserve Bank, Minneapolis, Minnesota 55480.

Articles may be reprinted if the source is credited and the Research

Department is provided with copies of reprints.

The views expressed herein are those of the authors and not necessarily those of the Federal Reserve Bank of Minneapolis or the Federal Reserve System. 


\title{
Should Currency Be Priced Like Cars?
}

\author{
Thomas M. Supel \\ Senior Economist \\ Richard M. Todd \\ Economist
}

Research Department

Federal Reserve Bank of Minneapolis

Today the price of a brand-new subcompact car is about $\$ 6,000$ whereas the price of a two-year-old subcompact car with 30,000 miles of wear is about $\$ 4,000$. This pattern of higher prices for new cars and lower prices for older cars is familiar and taken for granted by car owners.

Today the price of a brand-new dollar bill is $\$ 1$ (in the sense that you must give up $\$ 1$ in some form to get a new dollar bill). Yet the price of a two-year-old tattered or worn dollar bill is also $\$ 1$. This pattern of equal prices for new and old dollar bills is familiar and taken for granted by dollar bill owners.

Cars and dollar bills can both be viewed as durable assets-physical objects that are produced at some expense and that, once produced, deliver a flow of services over time until they finally wear out. (Here the services are transportation and transactions.) Yet new cars sell at a premium over worn cars while new dollar bills trade without a premium for worn dollar bills. Why should two durable assets be priced so differently?

An explanation, though not necessarily a good reason, for the difference is that cars, like most freely traded durable assets, are produced by the private sector while dollar bills and other forms of currency (bills and coins) are produced by the government. To cover costs and stay in business, automobile producers and dealers must charge more for new cars than worn cars. The U.S. government, however, in producing and selling new currency, need not worry about selling at a price that covers production costs because it can cover these costs with tax revenues. ${ }^{1}$ So the government is free to exchange new and old bills one-forone, or in general to exchange units of currency according to their face values, which is known as par pricing of currency.
The U.S. government has, of course, chosen to par price all bills and coins, regardless of denomination or physical composition as well as age, even though some bills and coins cost much more to produce than others. Whether or not this choice is the right one is, however, not clear. Par pricing definitely has flaws. According to economic theory, because par prices are not related to the costs of producing par-priced goods, par pricing almost certainly leads people to use too much of some goods. For currency, this means that almost the same level of transaction services might be obtained if other, less costly forms of money were used instead. But nonpar pricing of currency is not definitely better than par. Though it might improve the mix of currency, it would be much less convenient. If rates of exchange of different units of currency were not fixed by face values, then currency users would have to convert each of the different forms of currency into a standard unit of account, and the conversion rates could change constantly. In terms of society's well-being, this added inconvenience could overwhelm the benefit of an improved mix.

Unfortunately, no economic theory or evidence has yet established which of these arguments outweighs the other. We do think, though, that economists and the managers of the U.S. currency system (the Treasury and the Federal

${ }^{1}$ Seignorage alone, of course, more than covers the costs of adding to the stock of currency in circulation. Nonetheless, the government effectively finances currency production out of tax revenues. Seignorage is earned whenever the public buys an additional unit of unbacked government debt, not just when the debt instrument is a unit of currency. So the decision to issue the new unit of unbacked debt as currency is separate from the decision to issue the new unit of unbacked debt, and it is the latter that generates seignorage. Also, most currency is produced to replace worn-out currency, not to add to the stock of circulating currency. 
Reserve System) should seriously study some limited forms of nonpar pricing of currency. Par pricing of currency is, as we have noted, familiar, convenient, and largely taken for granted. However, it boosts the U.S. government's cost of providing currency, which now totals about $\$ 400$ million annually. And its potential for leading to costly overproduction of some forms of currency has apparently been so great that it has already caused the managers of the U.S. currency system to fruitlessly spend money promoting the use of less expensive forms of currency and even to deviate from strict par pricing principles. (See the box accompanying this article.) Both theory and practice seem to imply that strict par pricing leaves room for improvement in the U.S. currency system.

\section{Room for Improvement Under Par Pricing}

A widely accepted definition of an economic improvement is a change that makes at least one person better off without making anyone worse off. According to economic theory, par pricing of any group of goods and services generally leads to patterns of production and use of those goods and services that can at least potentially be improved on in this sense. This theory seems to apply to U.S. currency.

\section{General Potential}

The potential to improve on the results of par pricing generally exists because, unlike nonpar pricing, this pricing system fails to equate the rates at which users are willing to exchange goods and services with the rates at which technology allows their exchange.

Under a simple form of par pricing, for example, consumers could exchange any amount of one good or service in the par-priced group for an equal amount of any other good or service in the group. ${ }^{2}$ Theory says this onefor-one par price ratio would ultimately be the rate at which consumers would be willing to trade one par-priced good or service that they consume for any other. That is, being free to exchange goods and services in the par-priced group at the one-for-one ratio, consumers doing the best they could for themselves would adjust their use of these goods and services until giving up a unit in order to sell it and buy a unit of another would not make them any better off. Having exhausted all possibilities for improving their lot by exchanging goods and services at the par price ratio, consumers would be just willing to exchange them-that is, indifferent toward exchanging them-at this ratio.

To preserve par prices among a group of goods and services, the amount of each good and service produced must exactly match the amount consumers want to have at these prices (the amount, in fact, which makes them indifferent toward exchanging at par price ratios). Otherwise consumers would have more of some goods and services and less of others than the par prices had led them to want. These preferences would affect the relative prices of the goods and services. Consumers would bid up the prices of anything scarce until they were satisfied, that is, just willing to hold the amounts actually supplied. In other words, if par pricing is to be maintained, the supply of the goods and services involved must equal the demand at the par prices; otherwise the market will reject par pricing.

That par prices and consumers' preferences determine the production of each par-priced good and service means that technology (or the way resources are used in production) is irrelevant under par pricing. It affects neither prices, which are fixed at par, nor quantities consumed and produced, which are chosen by consumers based on the par prices. In private nonpar pricing markets, the forces of demand and supply make prices adjust to equate consumers' willingness to exchange one good or service for another to producers' technological abilities to transform them. Obviously, this would not happen in par-priced markets. Instead, any relationship between consumer preferences and technology would be accidental and fleeting. No forces would act to align the rate at which production of one par-priced good or service could be increased if consumers gave up one unit of another (the marginal rate of transformation between the two) and the par price ratio at which consumers are indifferent about exchanging goods and services (the marginal rate of substitution).

It is this almost certain divergence, under par pricing, between these marginal rates that creates the potential to improve on the results of par pricing. Under this system, almost certainly there will be some pair of goods or services such that producing one less of one of them would allow society to use the resources thus freed to produce more than one of the other. But since consumers will have adjusted to the one-for-one par price ratios, only one more unit of the other good or service will be needed to prevent anyone from being made worse off than before (that is, before the single unit of the first good or service was given up). The rest of the increased output of the other good or

2Less simple examples would involve fixed but not necessarily one-for-one price ratios. Currency, which trades at face value ratios such as five $\$ 1$ bills for one $\$ 5$ bill, provides this sort of example. The arguments above can easily be modified for price ratios other than one-for-one. 
service can thus be used to make at least one person better off. This result-no one worse off and at least someone better off-satisfies the common definition of an economic improvement. In saying that there is potential to improve on the results of par pricing, therefore, we mean that under par pricing there are almost certainly such rearrangements of the patterns of production and consumption that are technologically possible and would make at least one person better off without making anyone worse off.

If such rearrangements are technologically possible, why should we call them only potential improvements? The reason, as we shall see, is that their potential to make someone better off without making anyone worse off is not realized unless some new system can bring about the rearrangement without itself generating side effects that negate the advantages of the rearrangement.

\section{Potential With U.S. Currency}

The logic of this general argument is perhaps clearest when it is applied to the familiar case of currency-and, in particular, U.S. currency.

However, some care is necessary when making this application. In referring to currency as a commodity, we mean that the physical tokens-coins or bills-used to embody or signify ownership of the U.S. unit of account (the dollar) can be regarded as durable assets providing a stream of services (namely, proof of ownership) over time. We do not view the abstract unit of account as a commodity. At the same time, it is units of account rather than their tokens that par pricing insures exchange one-forone. To preserve one-for-one exchange among the units of account they represent, coins and bills exchange at the ratio of their face values (for example, ten $\$ 1$ bills for one $\$ 10$ bill, a paper dollar for a dollar coin, two quarters for five dimes, and a worn-out bill for a new bill of the same denomination).

Finally, since much of the information we have on currency technology is expressed in terms of the dollar costs of providing the various forms of currency, it will be convenient to note that the marginal rate of transformation between two goods is equivalent to the ratio of the two goods' marginal costs (the cost of producing an extra unit of one divided by the cost of producing an extra unit of the other). We can thus refer to the relative (marginal) costs of two forms of currency instead of to their marginal rate of transformation.

Now we can describe more concretely the preferences consumers have for currency and its various forms, the relative costs of providing currency and its forms, and the reason par pricing of currency has led to patterns of production and use that can potentially be improved upon.

\section{Preferences}

In choosing the total amount of currency they will hold, currency users weigh the relative advantages and disadvantages of currency and competing stores of wealth such as bank deposits, stocks and bonds, and commodities like metal. Currency has the advantage over many alternatives of being easy to carry and store, at least in small amounts. Because its face value is guaranteed by the government, currency can also be more convenient to pay (or accept in payment) than checks or credit, which often require that time and resources be devoted to verifying the payee's creditworthiness. Currency's disadvantages include its low rate of return (no interest or dividends); the risk that it will be irretrievably stolen or lost; and the inconvenience of carrying large amounts of it.

In choosing the mixture of the various forms of currency they will hold, currency users weigh the relative advantages and disadvantages of the various forms. User preferences-shown, for example, in the reluctance with which many people accept $\$ 2$ bills, Anthony dollars, and extremely worn or dirty currency-may reflect aesthetic feelings to some degree. However, they probably also reflect practical concerns about the relative convenience of holding and exchanging the various forms of currency. The inconveniences that currency users take into account when selecting a bundle of currency for the transactions they expect to make likely include the following: incurring ill will and spending time waiting for and counting change when a large denomination is exchanged for a low-cost item; not having the exact bills or coins when needed, such as for bus fare or coin- or bill-operated machines; having to carry large numbers of coins or small-denomination bills; losing money by misplacing coins or miscounting large amounts of change; losing money by erroneously accepting the lower-valued or paying the higher-valued of two physically similar types of currency or losing time by having to more carefully check the value of units of currency; and having to separately store many different forms of currency, such as in a cash register drawer.

\section{Costs}

The total annual costs of providing currency in the United States run at least into the hundreds of millions of dollars. In 1980, for example, the Federal Reserve System spent $\$ 200$ million to provide paper currency, and the Treasury 
Department spent a like amount providing coins. This nearly $\$ 400$ million annual expenditure included the costs of printing and minting currency; sorting circulated currency to remove unfit coins and bills and to group and store fit ones by type, as bags of quarters or bundles of $\$ 10$ bills, for example; distributing new and sorted fit currency to the public; and destroying and disposing of unfit currency.

A noteworthy feature of the costs of providing currency is that the relative costs of the various forms of paper currency are almost equal. Bills cost about two cents each to print, no matter what their face value. As a result, the cost of providing an extra ten units of account as ten $\$ 1$ bills, for example, is about ten times the cost of providing those units as one $\$ 10$ bill.

Another noteworthy feature of currency costs is that bills wear out much more quickly than coins and thus have to be replaced much more frequently. This advantage of coins is especially significant for small denominations, which change hands more often than large denominations and are thus subject to more intense wear. The advantages implies that, even if minting a coin of a small denomination costs more than printing a bill of the same denomination, over time the greater durability of the coin could make it a less expensive way to provide the denomination.

\section{The Result of Missing Incentives}

Currency users choose the total amount and mixture of currency they hold so that, based on their view of the relative advantages and disadvantages of the various forms of currency and other stores of wealth, they are just willing to exchange units of currency at par price ratios. However, as we have seen, the par price ratios reflect only the face value of the forms of currency and are often far from equal to the relative costs of providing these forms, which (for bills especially) are more nearly independent of face value. As in the general case, this divergence between the rates at which users are willing to exchange and the rates at which technology can exchange creates the potential to rearrange currency production and use so as to make someone better off and no one worse off. ${ }^{3}$

The main source of the potential to improve on the total amount of currency in use is the fact that par pricing of old and new bills precludes pricing to cover the nonzero costs of providing new bills. As a result, currency users adjust to price ratios between currency and competing stores of wealth that may reflect (for example, through per check service charges) the costs of providing the competing stores of wealth but don't reflect the costs of providing currency. Currency users adjust the amount of currency they hold until they are just willing to give up a dollar of currency and convert it to whatever face value of a competing store of wealth it will buy (net of the service charges or other fees needed to cover the cost of providing the noncurrency). No users would be made worse off by such a rearrangement of their portfolio. Yet almost certainly, if it could be managed, such a rearrangement would permit resources to be freed from currency provision to provide other goods that could make at least someone better off. In this sense, too much currency is likely to be produced and used under a par pricing system.

This possibility can be illustrated by returning to the comparison of auto and currency pricing. New car prices cover the costs of producing an extra car, and used car prices decline as the car wears out. From the perspective of society as a whole, trying to get the most from its resources, this type of pricing gives drivers an incentive to conserve on their use of both new and used cars, relative to competing means of transportation. Currency users have no comparable incentive to conserve on their use of currency, relative to competing means of exchange such as checks. ${ }^{4}$ Whatever amount of any form of currency they want they can get at face value, without paying anything toward the costs of eventually replacing what they are using and wearing out.

Par pricing leaves room to improve on the mixture as well as the amount of currency in use and for a similar reason. For example, a $\$ 10$ bill, as indicated above, is produced with about the same amount of paper, ink, labor, and other inputs as a $\$ 1$ bill, so that providing an extra ten $\$ 1$ bills costs about ten times as much as providing an extra $\$ 10$ bill. Under par pricing, however, the government is willing to exchange upon demand ten ones for a ten, and currency users adjust to this par price ratio until they too are just willing to exchange ten ones for a ten. A re-

3 Some readers may note that our assertion, here and elsewhere, that consumers' marginal rates of substitution equal the par price ratios is only true between pairs of goods that are both consumed. When one good in the pair is not consumed, an inequality results. This may raise concern over the validity of our argument for forms of currency (such as $\$ 2$ bills or $\$ 1$ coins) that circulate in small volume and are infrequently held by most currency users. Our argument can be modified to cover these forms, either by restricting the rearrangements of currency use to the set of users who do regularly handle these forms or by actually working with the inequalities. The modifications might reduce the size of the potential improvements over par pricing, but would not change our basic conclusions.

4To the extent that users of currency substitutes also do not directly pay for the costs of providing them (as, for example, in the case of so-called free checking), the potential for improving on the total amount of currency in use under par pricing is reduced; par pricing's incentive to overuse currency could be offset by these incentives to overuse the currency substitutes not being directly paid for. 
arrangement that shows the potential for improvement in this case is for each currency user to substitute one more ten for ten less ones, which would leave each of them no worse off while freeing for other uses (to make someone better off) the resources that would have been used to provide the nine extra bills.

Many similar examples come to mind, such as between coins and bills of the same face value, new coins or bills and old coins or bills, and coins or bills of differing face values. Appealing to the car analogy again, par pricing of the various forms of currency leads to the same kind of potential for improvement that would result if the government bought and sold the various makes and models of new and used automobiles at price ratios that reflected only their relative seating capacity.

\section{Par's Limitations}

The managers of the U.S. currency system have recognized the potential to improve on the existing patterns of currency production and use. However, par pricing limits their ability to achieve this potential and has recently thwarted several of their attempted rearrangements.

\section{Inadequate Tools}

Under par pricing the currency managers have only two policy tools for trying to rearrange the amount and mixture of currency in use, and both tools are inadequate.

One tool is to introduce or promote substitute forms of currency that cost less to provide (at the margin) than the heavily used forms they are meant to replace. This tool is not very risky-or very powerful. The risk is limited to the expense of printing or minting and holding an inventory of the substitute bills and coins plus the cost of advertising and promoting them. Since no one will be forced to use the lower-cost substitutes, the worst that can happen is that users will in fact not use them (or not use more of them than before), leaving users individually no better or worse off than before but leaving the currency managers, and hence the taxpayers collectively, with a fruitless expenditure on currency inventory and advertising. The problem with this low-risk policy approach is that the worst it can produce is quite often exactly what it does produce. As long as par pricing is maintained, currency users have no incentive to decrease their holdings of existing higher-cost forms of currency or to begin holding new lower-cost forms. Only if a new and less expensive to provide form of currency also gives users equivalent or better service than an existing form will it be accepted and thereby free resources from currency provision that can be used in another way to make people better off.

The currency managers' other policy tool is to simply abolish an existing high-cost form of currency, forcing users to switch to lower-cost substitutes. While obviously powerful, this tool is also quite risky because whether so drastic a rearrangement in currency use would be an improvement is hard to determine. For small changes in the patterns of currency production and use, we can be confident that the well-being of currency users is little affected; before the small changes, remember, the freedom to exchange currency at par would have already made users just willing to trade small amounts of any one form of currency in their portfolio for the same face value of another. With the well-being of currency users unaffected, small changes would be improvements as long as they reduced even a small amount the resources devoted to currency provision. However, for large changes, such as the abolition of a popular but relatively expensive form of currency, we cannot safely assume that the well-being of currency users will be unaffected. Instead, their well-being would decline by an unknown amount, making it hard to know whether the resources the change freed from currency provision could be enough to both restore currency users' well-being and make someone better off.

\section{Historical Examples: The $\$ 1$ Bill and Its Cheaper Substitutes}

Faced with this uncertainty, the U.S. currency managers seem to have been reluctant to abolish popular but relatively expensive forms of currency. In the case of the $\$ 1$ bill, for example, the managers have repeatedly relied only on their first tool-offering cheaper substitutes. Their repeated failures to get consumers to switch to these substitutes illustrate how hard it is to achieve the potential for an economic improvement under a par pricing system.

Because U.S. \$1 bills are heavily used and wear out quickly, they are an expensive form of currency. The Bureau of Printing and Engraving prints and distributes over 2 billion new $\$ 1$ notes each year at a cost of about 2 cents each, or over $\$ 40$ million total, and on average those bills last only 1.5 years. The same face value of currency now supplied by $\$ 1$ bills could be supplied at less expense by half as many $\$ 2$ bills. Alternatively, savings could be achieved by replacing $\$ 1$ bills by $\$ 1$ coins, which cost about 50 percent more initially but last many times longer.

At least three times in this century, these potential advantages of the $\$ 2$ bill and the $\$ 1$ coin have prompted the currency managers to offer them to the public at par as 
substitutes for the $\$ 1$ bill. In each case the public spurned the substitutes.

\section{The \$2 Bill}

In 1924 the Treasury faced a problem of increasing costs associated with the issue, redemption, and replacement of $\$ 1$ bills. It tried to get enough $\$ 2$ bills into circulation to reduce the number of $\$ 1$ bills outstanding by half, but as economist Neil Carothers (1930, p. 296) observed, it failed.

The circulation of the two denominations is undesirable. They are confused in change operations, and their joint circulation is a cause of dispute, annoyance, and occasional fraud. The \$2 notes are accepted reluctantly, passed on quickly, and driven back to banks and Treasury offices.

Based on these observations of users' resistance to the new bills, Carothers (1930, p. 297) framed the Treasury's options under par pricing:

There are two possible solutions. One is to abolish the $\$ 2$ note and provide an adequate number of $\$ 1$ bills regardless of expense. The other solution, more drastic but more fundamental, is to abolish the $\$ 1$ note.

The Treasury did not formally adopt either of these solutions until 1965 , when it stopped providing \$2 bills. The public, however, effectively solved the problem of joint circulation by choosing to use almost no $\$ 2$ bills.

Almost exactly 50 years after this episode, the Treasury was again concerned with the growing cost of providing $\$ 1$ bills. Studies indicated that the government could save several million dollars and postpone a major capital investment in currency production facilities if currency users would accept $\$ 2$ bills in place of ones.

The Treasury apparently hoped that an .advertising campaign could reverse its previous failure and persuade the 1970s public to accept twos. One study which influenced the decision to reissue $\$ 2$ bills noted that the "public has an inherent dislike for the two dollar bill" but concluded that this dislike was based on "correctable misconceptions" that could be dispelled with an appropriate educational campaign (Axelrod et al. 1975, pp. 4, 5).

Based on the potential cost savings and the hope that advertising could overcome the public's reluctance, the decision was made to reissue the $\$ 2$ bill as part of the nation's bicentennial celebration (in 1976). As in the 1920s, however, the results disappointed the currency managers. A total of only 575 million of the new $\$ 2$ bills were eventually printed, far fewer than the more than 2 billion $\$ 1$ bills printed annually. A substantial portion of the twos remained in storage in the Federal Reserve System, while the number of $\$ 1$ bills in circulation continued to grow rapidly. Without an incentive to switch from $\$ 1$ bills to $\$ 2$ bills, the public was unswayed by advertising and again rejected the less expensive form of currency, which may indicate that dislike of $\$ 2$ bills reflects more than misconceptions.

\section{The $\$ 1$ Coin}

Even as the U.S. public was rejecting the bicentennial \$2 bill, the currency managers prepared to introduce the Anthony dollar coin, another lower-cost substitute for $\$ 1$ bills. The managers were attracted to the idea of the Anthony dollar because, although these coins are actually more expensive to produce than dollar bills ( 3 cents each versus 2), they wear out so much more slowly that, if generally accepted, they could save tens of millions of dollars each year.

A study prepared before the introduction of the new coins (Martin 1979) warned the currency managers that they could expect no better luck with Anthony dollars than with $\$ 2$ bills. The study raised doubts that mere exhortation would get the dollar coin into circulation, noting that "there is a serious question whether the consumer or general public will accept the argument of a government cost saving as "the reason for' the new one dollar coin" (Martin 1979, p. 16). The study also repeated two traditional explanations for the unpopularity of dollar coins-consumers don't like to carry coins in general (and large-denomination coins especially), and dollar coins pose serious problems in retail trade because most cash register drawers don't have a separate compartment for them. Finally, the study pointed out that the physical characteristics of the Anthony dollar would reduce its chances of public acceptance. The Anthony dollar is distinctly smaller than previous dollar coins, such as the silver dollars of the nineteenth and early twentieth centuries and the more recent Eisenhower dollar. This smallness is an advantage, for one of the reasons why those earlier dollar coins did not circulate much is the inconvenience of carrying such large and heavy pieces. However, the smallness is a serious disadvantage as well. Along with the coin's round shape and silver color, the smallness makes it easy to mistake the coin for a mere 
quarter. $^{5}$

The authors of the study actually recommended forcing the Anthony dollar into circulation by simultaneously abolishing \$1 bills, but the currency managers rejected this advice. ${ }^{6}$ In 1979 , the new coin was introduced, advertised, and promoted, but the public was permitted to freely exchange $\$ 1$ bills and coins at par.

As the study had predicted, the results were almost identical to those of the bicentennial $\$ 2$ bill. The public continued to carry $\$ 1$ bills, well over half of the new coins wound up as inventory in the Federal Reserve System, many never made it into circulation at all, and production of the Anthony dollar was essentially halted in 1980 .

\section{Uncertain Alternatives to Par Pricing}

If par pricing leads to patterns of currency production and use that can at least potentially be improved on, yet that potential doesn't seem able to be achieved under par pricing, can it be under some form of nonpar pricing? The answer is not clear.

Under par pricing we can identify rearrangements of existing patterns of currency production and use that would be economic improvements. They would, that is, free enough resources from currency provision to produce enough other goods and services to both compensate currency users for any loss of well-being associated with their switch to the new amount and mixture of currency and make at least someone better off. The problem under par pricing is that such potentially superior rearrangements usually can't be made; the currency managers' tools-offering substitutes or abolishing existing forms of currency-are inadequate.

Nonpar pricing gives the currency managers more flexibility - through pricing - to offer the incentives necessary to bring about at least some of these rearrangements. However, nonpar pricing has side effects-the increased transaction costs associated with a more complicated currency pricing system-that may offset the potential improvement of the rearrangements. That is, nonpar pricing probably can bring about rearrangements that free enough resources from currency provision to compensate currency users for just the change in the amount and mixture of currency they hold. But these rearrangements may or may not free enough resources to compensate currency users for both that change and the extra inconvenience they experience in transacting with nonparpriced currency.

\section{A Powerful Tool: Pricing}

Unlike par pricing, which refers to a single specific system, nonpar pricing refers to any of many possible alternatives. In particular, it allows the currency managers to charge different prices for units of account depending on which forms of currency they are embodied in. The managers may charge, for example, more or less for a dollar coin than for a dollar bill and more or less for five \$1 bills than for one $\$ 5$ bill. Alternatively, they may limit (or ration) the supply of some forms of currency and let currency users determine its price in the marketplace.

Although nonpar pricing gives the currency managers flexibility in pricing currency, it gives them no direct control over the prices at which currency users will actually trade currency. Nonetheless, it seems likely that, by linking the managers' prices for the various forms of currency to the relative costs of providing these forms, the managers could induce users to make at least some improving rearrangements in currency production and use. Other improvements might be brought about by rationing relatively expensive forms of currency.

\section{Side Effects}

Despite the room it leaves for improvement, par pricing is a very convenient system for currency users. Under it, rates of exchange among forms of currency are well known and easy to calculate. Prices and contracts can be specified in units of account-dollars and cents-without much attention to the rates at which the various forms of currency will be accepted as payment. Furthermore, under par pricing, currency users are not exposed to exchange rate risk, or the possibility that the value of the forms of U.S. currency they hold will decline relative to other forms of that currency. In short, the agreement that par pricing

5 The study's conclusion was supported by historical precedent. In the last half of the nineteenth century, for example, the U.S. currency system contained a 3cent piece and a 20-cent piece in addition to the still familiar 1-,5-, 10-, and 25-cent pieces. However, "the public chose the silver dime, the copper-nickel 5 cent piece, and the bronze 1 cent piece as the only coins required in transactions involving less than 25 cents" (Carothers 1930, p. 273). The case of the 20-cent piece is especially interesting. This coin was issued in 1875 , not to reduce costs but to facilitate the transition in the West from Spanish and Mexican currency to U.S. currency (Carothers 1930, pp. 261-62). It was issued, however, without withdrawing the quarter dollar, a piece similar in size and value to the new coin. Apparently the resulting confusion caused limited circulation of the new coin, and Congress withdrew it after only three years.

6 There was a historical precedent in this regard also. In 1924 Secretary of the Treasury Andrew Mellon proposed as a solution to the mounting costs of supplying \$1 bills that those bills be abolished and the public be forced to use the silver dollars then languishing in the Treasury's vaults. His proposal was not accepted. 
insures between the face and market values of various forms of currency simplifies trade.

Some, and perhaps many, of these conveniences would be lost under nonpar pricing. The exact loss would depend on the exact nonpar system chosen, but some of the potential inconveniences of nonpar pricing of currency can be identified by first considering how nonpar pricing works for other durable assets, such as our durable example, automobiles.

Generally, if auto A costs more to produce than auto B, auto A will also cost more to buy. Some consumers choose to pay the higher cost of auto A because they expect, in one way or another, to get their money's worth from it. They may expect to keep their auto A until it wears out, thinking that its better performance or longer life, compared to the cheaper auto B, will compensate them for the extra money they spent on it. Alternatively, they may expect to keep their auto A for only a while, enjoying its better performance and then selling it. In this case, the likely resale price of their auto $\mathbf{A}$ is an important factor in the decision to buy it. Because even a used auto A should perform better or last longer than an auto $B$ with the same mileage and history of use, resale prices will also be higher for auto A than for auto B, partially compensating buyers of auto $\mathrm{A}$ for its higher initial price.

Now suppose that dollar bills and dollar coins were priced like automobiles. A new dollar bill might sell at face value (\$1) plus its cost of printing (\$.02), or \$1.02. A new dollar coin, because of its higher production cost $(\$ .03$ for minting), would sell for more, or $\$ 1.03$. Almost no users would buy either a bill or a coin with the thought of keeping it until it wears out, so the appropriate analogy is to an automobile which is resold before it wears out. With currency just as with cars, some consumers would buy the higher-priced form (dollar coins) despite its higher price if that form were either sufficiently more convenient than or had sufficiently higher resale value than the other (dollar bills). Again, the resale values of individual units would decline gradually as the units wore out.

In this system, many of the conveniences of par pricing would obviously be lost. Fixed rates of exchange among units of currency would be lost; bills and coins of various degrees of wear would take on relative values that would depend on those degrees. Therefore, to get full value from their currency in this system, currency users would have to determine the exact stage of wear of each bill or coin they encountered and calculate its exact current value, perhaps to many decimal places. Besides that, no longer would all

\section{Superfit Bills Bend Par Pricing}

Strict par pricing does not permit the currency managers to limit the use of high-quality (new, expensive) currency by either rationing or surcharges. For many years, good luck-in the form of widespread public indifference about the quality of U.S. bills-permitted the managers to maintain a nearly costminimizing level of bill quality in spite of par pricing. However, the spread of cash handling machines, which work best with very high-quality, or superfit, bills, may be bringing the managers' lucky streak to an end.

\section{Cost vs. Quality}

As it exchanges a large volume of currency with the private sector, the Federal Reserve System monitors and maintains the quality of the nation's circulating currency. When a bank deposits currency at the Fed, the bills and coins are examined for wear and tear. Those that are judged to be below minimum quality are destroyed and, if necessary, replaced with new bills or coins provided by the U.S. Treasury. The remaining fit bills are sorted by type and denomination, bundled, and stored until there is a demand for them again.

In this system, the choice of a minimum quality standard for currency is critical. It affects not only the quality of the circulating currency but also the cost of the Fed's sorting activity and the number-and hence the cost-of replacement bills and coins required from the Treasury.

The relationship between the level of these costs and the level of minimum fitness can be thought of as a $U_{\text {-shaped curve. For }}$ the partly mechanized technology in use since the mid-1970s, any reduction in the minimum quality standard causes the Fed's cost of sorting currency to increase and, below some point, to increase rapidly. This is mainly because the people and machines that sort currency can process high-quality currency faster than low-quality currency. Unlike the Fed's sorting cost, the Treasury's cost of providing replacement currency decreases as the minimum quality of currency is reduced, but it increases rapidly as minimum quality standards are raised. This is because a lower standard means that bills and coins last longer and are replaced less frequently. Combined sorting and replacement costs rise rapidly for either extremely low or extremely high minimum fitness levels.

units of currency function as units of account; their dollar values would vary with wear. In an uncertain world, where demand for bills and coins of various ages would be unpredictable, the relative exchange value of two used bills or coins would also be unpredictable. In short, trade under 


\section{Technology vs. Luck}

By influencing the quality of circulating currency, the minimum fitness level also affects the benefits the public derives from currency. Currency of very low quality is aesthetically displeasing to some, difficult to count and handle, and unsuited to certain uses, such as in vending machines or other mechanical currency processors.

Above a certain level of quality, however, further increases in the quality of currency - and hence in the minimum fitness level-usually don't matter very much to most people. For many years, in fact, most people did seem to be indifferent about bills within a broad range of quality levels. This allowed the currency managers to select a minimum level of bill quality which came close to minimizing quality-related costs. If people had not been so indifferent, they could have driven lower-quality bills out of circulation and raised the effective minimum bill quality to an expensive level, for maintaining par pricing in the face of a strong public preference for superfit bills would require a sharp increase in the costs of printing replacement bills. In a par pricing system, where currency users don't bear the increased printing costs, such a preference for superfit bills would produce a large potential for economic improvement (which could be realized by lowering the minimum quality level of bills).

The rapid spread of automatic teller machines (ATMs) and other cash handling machines in the last few years may be creating just such a public preference for superfit bills. The number of ATMs alone reached almost 24,000 by mid- 1982 and has been doubling about every two years (Bradley 1982). These machines work best with either new or superfit bills; bills near the current minimal quality level or even bills of average quality can jam the machines. Therefore, ATM owners-chiefly banks and other financial depository institutions-have a rapidly growing demand for bundles of either new or superfit currency. ${ }^{1}$

Perhaps because accommodating this demand would drive printing costs up sharply, the currency managers have so far refused to guarantee the availability of bills sorted by quality. The managers have instead instructed the Federal Reserve Banks that requests for replacement currency, including bills, "be filled according to the inventory of cash on hand and that reusable currency and coin be paid out before the new uncirculated items are distributed" (FRB 1981, p. 4). In other words, banks and other ATM owners who order bills from the Fed usually receive bundles of mixed quality, ranging from new and superfit to barely minimal. If the owners need only high-quality bills for their ATMs, they have to sort out these bills themselves.

Although this policy has prevented currency printing cost increases, strictly speaking it is a deviation from par pricing. The managers are refusing to exchange at face value ratios two existing forms of currency-low-quality and high-quality notes. Economic theory suggests that the managers' policy should lead to both private sorting of bills and private premiums on sorted bills to pay for the cost of sorting. Private sorting is certainly occurring, for the ATMs are being stocked primarily with highquality notes. Private premiums are almost as certainly being paid for these high-quality notes, though the form of payment may not be very noticeable yet. ${ }^{2}$ To the extent that premiums are being paid, par pricing has broken down further, and the rapid spread of ATMs may erode it still further. The threat of rapidly rising printing costs may make the currency managers unwilling to preserve par pricing by supplying bundles of high-quality currency at par, and any scheme by the managers to charge more for bundles of high-quality bills would amount to an open and official abandonment of par pricing.

The managers' strategy in this situation currently seems to be to ask for technological changes that would bring back the kind of indifference about bill quality that for many years allowed them to both par price and choose a nearly cost-minimizing level of bill quality. Apparently the managers have suggested that manufacturers should develop new ATMs that can use lower-quality bills than today's machines can (Bradley 1982). Without such machines, the currency managers may face the choice of either incurring large cost increases or continuing to deviate from strict par pricing of bills.

1 This preference apparently does not extend to bundles that mix new and superfit currency. Many ATMs can be set to run on either new or superfit bills (the switching procedure takes about three minutes), but not on a mixture of both (Bradley 1982).

2 Some reasons such premiums might be hard to detect are that they could be lumped in with other fees or be paid in kind rather than cash. For example, they might take the forms of slight additions to existing costs of access to ATMs or, in the interbank market, long delays by one bank in filling orders by another bank for high-quality notes unless the ordering bank made enough concessions in other matters (for example, correspondent balances) to cover the costs of this service. nonpar pricing would be more complicated and less convenient than under par pricing.

\section{Questionable Results}

The greater transaction costs associated with nonpar pricing cast doubt on the relative advantages of this type of system in at least two ways. They limit the types of nonpar pricing that currency users would likely practice and thus the types of rearrangements in currency use that nonpar pricing can actually bring about. And for any rearrange- 
ment that nonpar pricing can bring about, they raise the possibility that the additional inconvenience of nonpar pricing itself outweighs any gain from the rearrangement. ${ }^{7}$

Certainly, the inconvenience of nonpar pricing limits the forms of nonpar pricing that currency users would practice. This is not very limiting for expensive goods such as automobiles; for them, the time and effort spent to determine the exact quality and value of the goods being bought or sold would be small relative to their differences in value. ${ }^{8}$ However, many goods that are less expensive to produce (and accordingly have lower price differentials) are not priced in as much detail as they could be. Meat prices, for example, vary by the official grade of the meat sold, but the true quality of meat actually varies somewhat within each grade. The cost of grading meat more precisely-creating more, narrower grades - could easily exceed the gains that more precise meat pricing would bring about. In the same way that meat buyers and sellers choose to recognize only a few quality and price classes for meat, buyers and sellers of currency in a nonpar system would likely recognize only a few classes of wornness and prices for coins and bills. In fact, given the relatively small cost differences (and hence probably small price differences) between the quality classes, they might even decide that keeping track of any classes would not be worth their trouble.

By limiting the forms of nonpar pricing that currency users would practice, the inconvenience of nonpar pricing makes some rearrangements of currency use impossible. It can also cause the currency managers' nonpar prices to have unintended deleterious effects. For example, suppose the currency managers decided to sell new currency at face value plus cost of production, which would be analogous to the pricing of new automobiles. Suppose also that currency users found all forms of nonpar pricing inconvenient and effectively imposed par pricing in the market for used currency. Buyers of new currency would know that they would later receive only face value for whatever they buy. Then they would, for example, avoid Anthony dollars, which would cost more than paper dollars, even more than they avoid them now under par pricing. ${ }^{9}$ So this official pricing policy, though designed to encourage currency users to conserve on their use of expensive forms of currency in the same way that nonpar pricing of automobiles encourages drivers to conserve on their use of expensive automobiles, would backfire: if combined with a choice of par pricing by the currency users, it would cause U.S. currency users to choose more, not less, of the relatively expensive dollar bills. Other official nonpar pricing systems could be similarly thwarted by the public's complete or partial unwillingness to price currency at nonpar ratios. This is one reason why the inconvenience of par pricing makes it hard to determine whether nonpar pricing systems would actually improve the U.S. currency system.

For those rearrangements of currency use that the currency managers could bring about with nonpar pricing, the uncertainty over the relative advantages of nonpar pricing is simply a difficult empirical question. Can currency users be compensated for the added inconveniences of nonpar pricing as well as for their switch to a possibly less preferred mixture of currency with the new goods and services produced from the resources that the rearrangement freed from currency provision? We know of no studies that answer this question, and we regard the relative advantages of par and nonpar pricing of currency as simply unknown at this time.

\section{Options Worth Studying}

Par pricing of currency can potentially be improved on, but nonpar pricing is less convenient and, as a result, may not actually be better. What should the currency managers do? Because par pricing of currency is familiar and widely accepted and because currency provision accounts for a small proportion of the federal budget, it might seem that they should simply heed a new version of the old saying: "If you're not sure it's broken, don't fix it." We tend to agree with this advice, for we are not convinced that any major change in our currency system should be made now. We also recognize that changes have to be carefully considered, for misguided reforms could easily do more harm than good.

\footnotetext{
7 We ignore some other doubts about whether a change to nonpar pricing of currency would actually improve the patterns of currency production and use-for example, whether the increased production of other goods made possible by the resources freed from currency provision actually would be distributed to currency users so as to make them no worse off and whether the economy has other resource misallocations that happen to be offset more effectively by par than by nonpar pricing of currency (the so-called problem of the second best). Unlike the doubts we discuss in the text, these are general doubts that apply to almost all economic changes; they seem to have no special relevance to the currency system.

${ }^{8}$ However, when the inconvenience of ascertaining the quality of an automobile does become large relative to the price of the automobile, the volume of trading in automobiles may vary inversely with quality. See Akerlof 1970.

${ }^{9}$ First users of currency might be willing to take some losses of this type. A bank, for example, might take these losses as a service to its retail customers, who might in turn compensate the bank through a hidden fee, such as a below-market rate of return on deposits.
} 
We do think, however, that improvements over the existing U.S. par pricing system are possible and should be seriously investigated. Examples such as the $\$ 1$ bill and its cheaper substitutes show that this nation has an already significant potential to improve on existing patterns of currency production and use and that this potential can't be achieved under par pricing. Furthermore, changes in technology, resource availability, or currency user likes and dislikes can, by altering the relative costs of or the demands for the various forms of currency, cause this potential to quickly increase. In fact, this has happened twice recently: a surge in the cost of copper temporarily made pennies much more expensive, and the spread of automatic teller machines (ATMs) has boosted the demand for high-quality bills. In both cases the managers responded by quietly introducing rationing - $\mathrm{a}$ hidden form of nonpar pricing-into our currency system. (See the accompanying box for a discussion of the case of highquality bills. ${ }^{10}$ ) Open and official nonpar pricing of currency should at least be studied in order to better understand the currency system we already have and the one we perhaps should have.

The current lack of empirical and theoretical knowledge about the inconveniences of nonpar pricing implies that, in studying nonpar alternatives, economists will initially have to turn to introspection and common sense for guidance. One practical criterion for evaluating nonpar pricing proposals is that at a minimum they should not backfire. That is, nonpar pricing systems should not worsen the pattern of currency production and use (by making currency less convenient or more expensive, without offsetting gains) even if, as is quite possible, currency users choose to practice in trades among themselves either par pricing or a more limited form of nonpar pricing than the currency managers practice in their trades with currency users. Beside rationing, which the currency managers have already used with some success, we think that at least two other types of nonpar pricing might meet this criterion.

\section{First-User Premiums}

The essence of first-user premium schemes is for the currency managers, when selling currency to depository institutions, to place modest surcharges on expensive forms of currency. The depository institutions paying these surcharges then would be free to price their currency as they saw fit. Although the exact effects of such schemes would depend on how the private sector decided to price the expensive forms of currency, appropriate first-user charges seem to create a no-lose situation for the currency managers. On the one hand, if the modest surcharges, however passed on in the private sector, caused a significant shift from expensive to less expensive forms of currency, then the public's preference for the expensive form was probably not strong enough to justify the extra expense of providing it in its previous quantities. On the other hand, if the public did not significantly decrease its use of the expensive form of currency, then the modest surcharge could be defended as an efficient tax, for it would raise revenue without strongly influencing the economy's allocation of resources.

The appropriate pattern of surcharges need not resemble the pattern of premiums on new units of currency in the ideal pricing-like-autos scheme. Those premiums would reflect the relative costs of printing or minting new currency, so that the premium on a new dollar coin would be higher than the premium on a new dollar bill. The firstuser surcharges could, by contrast, reflect something like the relative annual average costs of keeping the stock of each form of currency in circulation, so that the great durability of the dollar coin would earn it a smaller surcharge than the short-lived dollar bill, for example. As long as the first-user premiums were small (that is, less than the cost of producing a unit of currency) and were higher on more expensive than on less expensive forms of currency, the no-lose situation would seem to hold.

Setting surcharges in this way would yield a more practical system than the pricing-like-autos system. With these surcharges, the first user of currency distributed by the currency managers would have an incentive to choose the less expensive forms of currency even if par pricing in the private sector prevented the currency managers' prices from being passed on to subsequent users. Banks would get $\$ 1$ coins or $\$ 2$ bills at more favorable rates than $\$ 1$ bills, giving them an incentive to in turn encourage their customers to accept the less expensive forms. ATM owners could get all the high-quality notes they wanted, though at a fee. Par pricing would probably still predominate in private transactions, or at least the deviations might be subtle, with slight discounts and surcharges for use of the various forms of currency being bundled into other

\footnotetext{
10The penny shortage of the late 1970 s and the early 1980 s seems to have been resolved by a combination of luck - $\mathrm{a}$ fall in the price of copper-and action by the currency managers, who since 1982 have been phasing out the copper penny, replacing it with the cheaper copper-zinc penny, and increasing supply to meet the demand at par (Dorfman 1982).
} 
charges, such as correspondent balances, check cashing fees, or cash card fees, on an average cost basis. The private sector is already coping in this way with some deviations from par pricing of currency, including the refusal of the currency managers to supply on demand bundles of superfit bills (see the box) as well as the Federal Reserve System's policy of charging for physical delivery of bills by weight rather than face value. ${ }^{11}$

\section{A Lottery}

Another nonpar option worthy of serious study is for U.S. currency managers to follow the lead of countries which use lotteries to promote the sale of government debt. Purchasers of the debt receive numbered bonds that entitle them to a certain sum of cash in the future as well as a chance to win a jackpot if the serial number of one of their bonds is selected in a drawing. Some U.S. banks have acted similarly when promoting the use of their ATMs with random rewards by, for example, mixing a few $\$ 20$ bills into the piles of $\$ 5$ bills that the machines dispense (Curley 1982). Such schemes might overcome the barrier of habit which seems to hinder the introduction of new forms of currency (and which advertising has not surmounted). ${ }^{12}$ Suppose, for example, that the managers sought to circulate their large inventory of $\$ 2$ bills by running a lottery on the serial numbers of these bills. Some problems would have to be solved, ${ }^{13}$ but as long as the amount of money spent on the lottery were less than the amount the managers saved through reduced circulation of the expensive $\$ 1$ bill, the currency system might be improved.

\section{Concluding Remarks}

Although the relative advantages of par and nonpar pricing systems for currency are still uncertain, some nonpar pricing plans seem worthy of at least further exploration. Such exploration might not be supported by those who believe that currency is inherently a public service that should be financed by general tax revenues rather than by user fees. However, even if it can be shown that currency provision is properly a public enterprise, it does not follow that currency must be priced at par.

\section{References}

Akerlof, George A. 1970. The market for "lemons": Quality uncertainty and the market mechanism. Quarterly Journal of Economics 84 (August): 488500 .

Axelrod, Joseph; Bloom, Sonny; Brines, Jane; Costa, Cynthia; Mansfield, Ann; Moot, Suzanne; and Willert, Mark. 1975. The feasibility of reintroducing the two dollar bill: A marketing approach. Executive summary of report prepared for Board of Governors of the Federal Reserve System. Boston: Harvard University, Graduate School of Business Administration.

Bradley, Barbara. 1982. That tattered old currency can't hack it with the automatic tellers. Christian Science Monitor (September 20): 15.

Carothers, Neil. 1930. Fractional money: $A$ history of the small coins and fractional paper currency of the United States. New York: Wiley.

Curley, John. 1982. In some places, automatic tellers slip customers a little extra cash. Wall Street Journal (October 1): 27.

Dorfman, John R. 1982. Cents and sensibility. Forbes (May 24): 142.

Federal Reserve Bank of Dallas (FRB). 1981. Currency and coin. Dallas: Federal Reserve Bank of Dallas.

Martin, Claude R., Jr. 1979. Phase one: Research study into market acceptance of the new one dollar coin. Report prepared for Federal Reserve Bank of Chicago, Detroit Branch. Ann Arbor, Michigan: University of Michigan, Graduate School of Business Administration, Division of Research.

11 This means, for example, that a bank's delivery cost for $\$ 2$ worth of $\$ 2$ bills is half its delivery cost for $\$ 2$ worth of $\$ 1$ bills. Public par pricing of $\$ 1$ and $\$ 2$ bills survives in the face of this discrepancy.

12This idea was suggested by Martin Feldstein, but he should not be held responsible for any errors we have made in explaining it.

13 For example, the dates of the drawings would have to be unpredictable, so that people would not simply rush to banks on the day before the lottery to acquire large numbers of $\$ 2$ bills which they would hold only for one day. Procedures might be needed to handle cases where the winning bill was lost or in government vaults, and these could entail burdensome record keeping. 